\title{
Priorities, Partners, Politics
}

\section{The WHO's Mandate beyond the Crisis}

\author{
Tine Hanrieder \\ London School of Economics and Political Science, London, United \\ Kingdom and WZB Berlin Social Science Center, Berlin, Germany
}

\section{$1 \quad$ Introduction 1}

The ongoing pandemic is accompanied by intensive debates about the mandate of the World Health Organization (WHO) in emergencies. Should it be allowed to send inspections to countries? Does it have enough capacity to engage in surveillance and response? Most states currently seem unwilling to dismantle or replace the agency, but rather ask: How should it be strengthened beyond the pandemic, and in which areas?

These debates are being had against the backdrop of an organization that has been weakened over decades, and which is often described as an organization that has "lost its way."2 It is taking on (too) many issues, often on donor demand, and nowadays sources 80 percent of its budget through voluntary, often project-specific contributions. The result: it gets lost in "underfunded mission creep" 3 and is often an implementer rather than a leader.

There is no dearth of reform proposals on how to improve the WHO's leadership and impact. They are often couched in language borrowed from the consultancy world - be strategic, set priorities, find a niche and your competitive advantage among the many other global health actors. Yet such advice can help to only a limited extent, given the underlying normative controversies and lack of political commitment.

This essay reflects on these problems by going through three proposals for reinventing the WHO: 1) focus on pandemics; 2) keep your broad conception of health but set priorities: and 3 ) find your niche. None of these

\footnotetext{
1 The author thanks Luis Aue and the reviewers of Global Governance for their comments.

2 Moon et al. 2015, 2216.

3 Levine 2006, 1015 .
} 
prescriptions will work as long as the WHO is kept in a state of dependency by design, and thus prone to capture.

\section{$2 \quad$ Focus on Pandemics}

One suggestion is to narrow the WHO's mandate to improve its impact in strategic areas. While opinions diverge on what this core should be about, broadly speaking there are two variants of this suggestion. The first is to narrow its mandate to fighting pandemics; the second is to keep an encompassing outlook on public health, but set strategic priorities. Let us look at the first option. A radical reform proposal for the WHO would be to have it work only on highly contagious infectious diseases. ${ }^{4}$ This might not be the mainstream view among WHO friends and observers who value the broad definition of health enshrined in the WHO's constitution. Yet the idea to prioritize infectious disease reflects the spirit of the day and the sense of urgency produced by the devastating COVID-19 pandemic. It also reflects the ingrained modern worldview that health is a biomedical problem and that health care is about fighting disease.

And indeed, one of the most visible functions of the $\mathrm{WHO}$ is to protect states and humankind against disastrous pandemics. It is in this area that its coordinator role - for states, experts, laboratory networks - is relatively well established and where it enjoys formal authority thanks to the International Health Regulations (IHR). ${ }^{5}$ Certainly, this authority is deficient—-for example, the WHO does not have the means to independently verify outbreak rumors. Also, mistakes have been made in the past as well as during the current pandemic. Yet most states hold on to the WHO's crisis-fighting functions, and an important part of WHO reform debates focuses on how to make the IHR more effective-for example, by strengthening the expert bodies who oversee the WHO's emergency politics or by granting on-the-ground inspection powers to the WHO.

Realistically speaking, though, more intrusive surveillance and control powers for the WHO will be hard to achieve. Many states, not only China, will hardly allow the WHO to gather its own disease intelligence. Outbreak reports and travel warnings harm national economies and, this should not be forgotten, are just as much feared as pandemics. What is more, especially in times of cri-

4 Gadenne and Ghatak 2020.

5 Zacher and Keefe 2008. 
sis and insecurity, states are eager to display their sovereignty at their national border. COVID-19 is the best illustration. The myriad border controls for people and goods, including export bans for critical supplies, emphasize governments' desire to "wall" themselves and perform sovereign control. ${ }^{6}$ Against the backdrop of crisis nationalism, the backlash against multilateralism, and rising suspicion of expertocracy in many parts of the world, it is unlikely that the majority of WHO Member States will agree on a sweeping act of delegating more crisis fighting powers to the organization.

Additionally, an exclusive focus on infectious disease would dramatically truncate the WHO's mandate in global public health. Pandemics have deeper causes, which range from housing and agricultural systems to health system preparedness. Furthermore, ill health is not only caused by pandemics, but to a significant extent produced by causes other than infectious diseases (e.g., cancer and heart disease), and these again are conditioned by transnational determinants such as food security, education and, ultimately, the order of the global economy. ${ }^{7}$ This is reflected in the WHO's portfolio, which includes topics such as tobacco control, road safety, and sexual and reproductive health, to name just a few. In these areas, much of the WHO's work consists of gathering information, issuing technical guidelines for health providers and policymakers, and formulating policy options - activities that public health actors value and routinely draw on. Taking this breadth of the WHO's mandate into account, a second variety of the "narrow your mandate" recommendation is supportive of a broader WHO portfolio, but still insists on the need to set priorities.

\section{$3 \quad$ Set Priorities}

The advice that the WHO should set priorities is often voiced — even by those who do not ask it to focus on pandemics only. An organization whose budget is around the size of that of a big university hospital has its limits. And this even more so since, as emphasized above, its funding is strongly project oriented, often ad hoc, and generally demand driven. This makes it hard for the organization to sustain its activities or resource them adequately. Staff are increasingly short term, and the continuation of WHO projects must be continuously renegotiated.

6 Brown 2010; Ferhani and Rushton 2020.

7 Sell and Williams 2020 . 
Priority setting, here, will help to escape the project spiral. Additionally, it will help to specify the targets and outputs that the WHO generates. To achieve these two aims, the past decades have seen myriad reform endeavors aimed at clarifying the WHO's strategic goals and core activities - often with the help of management consultancies. At least since the organizational overhaul initiated by Gro Harlem Brundtland (WHO director-general 1998-2003), priorities figure prominently in speeches by directors-general, in official programs of work, and in reform proposals by expert committees; for example, the panel on WHO reform convened by scholars based at Harvard and at the London School of Hygiene and Tropical Medicine in the wake of the 2014 West African Ebola epidemic. $^{8}$

Yet such endeavors hardly ever become concrete enough to be implemented. While classifications of WHO priority types are countless, they are also short lived. ${ }^{9}$ Some designate broad areas of health policy; for example, emergency preparedness versus noncommunicable diseases. Others refer to types of WHO activities such as "proactive, active, and passive" WHO roles in global health affairs, ${ }^{10}$ or types of governance functions it can assume, ranging from the provision of global public goods to mobilizing global solidarity. ${ }^{11}$ These are best described as reflections on how to set priorities at some point in the futureor, to use words of a previous director-general from her announcement of a new priority setting exercise, "a framework for thinking about priorities and making wise decisions." ${ }^{12}$

Underneath the conceptual challenge of defining the right core areas for the WHO lies a political challenge: states and other shareholders would first need to come to a collective agreement on what the WHO should be asked to do. In reality, though, donors like to retain control of the activities they fund and to claim credit for visible activities such as, for example, polio eradication. By contrast, they have often shown that they are ready to reign in or punish the WHO when it ventures into terrains that touch on national industries or interests. For example, the WHO's Model List of Essential Medicines, introduced in the 1970s as a guidance for states and their health system priority setting, was fiercely opposed by big pharmaceutical manufacturers. It also led the United States to withhold financial contributions and push for a freeze of the WHO core budget. ${ }^{13}$

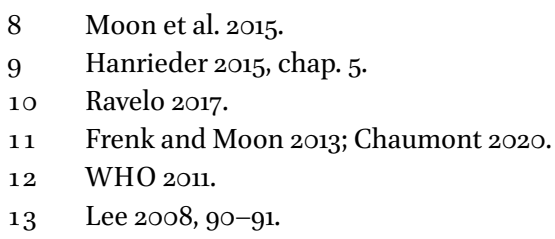


States can also decide to circumvent the WHO, or WHO-supported policies, where they disagree with its work. For example, the WHO's efforts to attenuate the public health impact of the Agreement in Trade-Related Aspects of Intellectual Property Rights ([TRIPS], concluded in 1994 as part of the World Trade Organization) was initially opposed by many manufacturers and governments. ${ }^{14}$ The WHO's legal interpretation of TRIPS supported, for example, the use of compulsory licenses and contributed to a clarification of public health rights through the 2001 Doha Declaration on the TRIPS agreement and public health. This declaration, however, subsequently lost some of its impact due to new strategies of circumventing it. Many states later simply bypassed it and concluded bilateral trade agreements with other states, so-called TRIPS-plus agreements, whose provisions prioritize intellectual property protection to the detriment of public health concerns. ${ }^{15}$

The WHO's priorities are worth little without buy-in by its shareholders. These shareholders can decide to defund contentious areas of the WHO's work or exit to other venues of global health governance. Indeed, competition from alternative providers of global health services - major public-private partnerships (PPPs) such as the Gavi Alliance, other multilateral organizations such as the World Bank, or humanitarian nongovernmental organizations (NGOs) such as Médecins Sans Frontières-has long been present in WHO reform debates. It motivates a further type of reform advice to the WHO: that it will take these other players into account when finding its competitive advantage.

\section{$4 \quad$ Find Your Niche}

In line with the new public management speak so prominent in the global health world, the WHO is often thought of as a provider of services in a crowded global health market. In this market, other providers-international organizations, NGOs, or also business actors-might be better equipped in certain respects. They may have better logistic capacities, more financial clout, or more relevant networks and know-how for certain tasks. The need for the WHO, then, is to demonstrate its relevance in comparison to these other providers and, to use a popular phrase used in this context, find its "competitive advantage."

\footnotetext{
14 Chorev 2013.

15 Drezner 2009.
} 
WHO leaders therefore often act as salesmen and saleswomen and market their product to interested investors. They develop "investment cases" to attract funding, and they strive to find the right brand for their agency. Even diplomats closely familiar with the WHO's work - and thus in no need of being enlightened about the nature of its work-encourage it to become more prolific at fund-raising, so as to compete with more versatile marketeers such as the UN Children's Fund (UNICEF).

However, the WHO brand is not an easy sell. Policy guidance is not as tangible as vaccines distributed, for example. What is more, a central and official role of the WHO, its constitutional mandate to act as the UN's "coordinating" agency for global health, does not fit well with the niche imagery. How can your niche be to guide the others, connect their expertise and data, maybe even direct them? Why would they accept this? And who funds such work? These are perennial problems for the WHO, played out in many local conflicts in the PPPs it is engaged in. The WHO often is dependent on the contributions of other health organizations: the research and training provided by its more than 800 collaborating centers, the data gathered by national or private laboratories, the expertise of specialists from the private sector, the logistics of public and private organizations, and lately the donations made to its newly established WHO Foundation.

Therefore, the WHO is often struggling to assert its independence and authority vis-à-vis its partners. This is particularly acute for partners from the private sector. Where these seem to unduly influence WHO decisions or guidelines, its legitimacy as a public interest organization suffers. Its close engagement with the private sector, or with individual experts closely entangled with for-profit organizations, has repeatedly caused problems. Its initiative with Interpol and major pharmaceutical associations to fight trademark violations in medicine production and trade $\mathrm{e}^{16}$ or its hastened recommendation of pharmaceuticals against "swine flu"17 are just two prominent examples where the WHO's credibility suffered because of the suspicion of undue private influence.

Given the need to assert the WHO's integrity in a world of public-private partnerships, efforts to develop and implement clear conflict of interest policies go back at least to the turn of the millennium. Yet arguably, these are not wholehearted efforts. A study of the WHO's PPPs in the Brundtland era found that conflict of interest policies were weakened by opposition from Member States and diffused within the organization. ${ }^{18}$ Little seems to have changed in

\footnotetext{
16 Paun 2012.

17 Hanrieder and Kreuder-Sonnen 2014.

18 Richter 2004.
} 
between. While public pressure has led to the negotiation of a new Framework for Engagement with Non-State Actors (FENSA, 2016), this new guideline is just as controversial.

WHO leaders and diplomats tend to warn that FENSA could become a bureaucratic monster inhibiting even low-key interactions with external experts. During the negotiation period, a nonpaper from the WHO even warned against embargoes against working with certain industries such as the arms industry due to its crucial IT, m-health and e-health expertise. ${ }^{19}$ The WHO's current director-general Tedros Adhanom Ghebreyesus, who assumed office when FENSA was already negotiated, has repeatedly assured WHO stakeholders that "FENSA is not a fence." It thus is not surprising that a first evaluation of FENSA's application at the WHO found that there was a lack of clarity and leadership on how to work with the framework. ${ }^{20}$ It is still unclear how FENSA will play out in practice. Furthermore, it leaves important gray zones such as the work with consultancy firms, which is technically a "procurement" and therefore not covered by FENSA.

The WHO's search for friends and the governance of public-private partnerships will remain high on the global health agenda. In an ideal world, the WHO as a public interest organization would have a strong voice in setting the rules for such partnerships. Yet as the current race for drugs against COVID19 shows, the WHO is only one among many players. The WHO facilitates scientific exchange, supports COVID-19 research, and provides guidance on many aspects of the pandemic. It is also a coinitiator of the Access to COVID19 Tools (ACT)-Accelerator, which bundles the energies of many institutions and donors to "to accelerate development, production, and equitable access to COVID-19 tests, treatments, and vaccines."21 Furthermore, the organization, through an expert commission, has developed preliminary guidance on who should be the first to receive a vaccine, once and if a safe and effective vaccine becomes available. This guidance, once fully developed, will certainly become a reference for many health policy-makers, next to nationally developed recommendations such as the draft plan developed at the US National Academies of Sciences, Engineering, and Medicine (NASEM). ${ }^{22}$

Yet the current politics of vaccine research and development also shows the limits of WHO leadership. Its initiative for a patent pool offering patent-free

\footnotetext{
19 WHO 2O15.

$2 \mathrm{O}$ WHO 2019.

21 WHO 2O2Oa.

22 Subbaraman 2020.
} 
licenses of anti-COVID-19 drugs to whoever wants to manufacture them has been joined by only forty Member States. ${ }^{23}$ Most high-income states prefer to have their own national strategies and bet on specific substances through advance purchase agreements. They engage in supplementary international cooperation through one strand of the ACT-Accelerator, the COVAX Facility, which is led by the Gavi Alliance, the Coalition for Epidemic Preparedness Innovations (CEPI), and the WHO. COVAX will pool procurement and, thereby, achieve economies of scale and ensure equitable vaccine distribution. Yet it remains contested given that potential barriers imposed by patents are not addressed, contracts with manufacturers are not transparent, and civil society has little voice in it. ${ }^{24}$ In this facility, the WHO clearly is a "partner"-not a coordinator-a position that reflects its shrinking "niche" in the global health space.

\section{5}

\section{Conclusion}

For the WHO, after the reform is always before the reform, and new generations of reformers tend to repeat messages that have circulated in Geneva for decades. Among these, managerial visions - such as priority setting, strategic budgeting, measurable outcomes, and finding a competitive advantage-are constant aspirations. The WHO, meanwhile, struggles to find a definition of its normative work that resonates with the language of markets. This struggle reflects the rise of public-private arrangements, and the celebration of "partnerships" by the WHO's big shareholders.

Such marketing is time consuming and probably inevitable, as long as the $\mathrm{WHO}$ is precariously funded. Yet it should not detract reformers from the fact that managerial cleverness is not a remedy for political vulnerability. Without a clear reform momentum from the side of WHO shareholders and, ultimately, without a new global social contract for public interest policy-making, the WHO's ability to further global public health will remain limited.

23 WHO $202 \mathrm{Ob}$.

24 Phelan et al. 202O. 


\section{Bibliography}

Brown, Wendy. Walled States, Waning Sovereignty (New York: Zone Books, 2010).

Chaumont, Claire. "Opinion: 5 Ways to Reform the World Health Organization." Devex, 5 August 2020. https://www.devex.com/news/opinion-5-ways-to-reform-the-world -health-organization-97843.

Chorev, Nitsan. "Restructuring Neoliberalism at the World Health Organization." Review of International Political Economy 20 (4) (2013), 627-666. DO I 10.108o/og69229o.201 2.690774.

Drezner, Daniel W. All Politics Is Global: Explaining International Regulatory Regimes (Princeton: Princeton University Press, 2009).

Ferhani, Adam, and Simon Rushton. "The International Health Regulations, COVID-19, and Bordering Practices: Who Gets in, what Gets out, and who Gets Rescued?" Contemporary Security Policy 41 (3) (2020), 458-477. DOI 10.1080/1352326o.2020.1771955.

Frenk, Julio, and Suerie Moon. "Governance Challenges in Global Health." New England Journal of Medicine 368 (10) (2013), 936-942. DOI 10.1056/NEJMra11o9339.

Gadenne, Lucie, and Maitreesh Ghatak. "The World Health Organization: A GRID for Reform." Vox, 30 May 2020. https://voxeu.org/article/world-health-organization -grid-reform.

Hanrieder, Tine. International Organization in Time: Fragmentation and Reform (Oxford: Oxford University Press, 2015).

Hanrieder, Tine, and Christian Kreuder-Sonnen. "WHO Decides on the Exception? Securitization and Emergency Governance in Global Health." Security Dialogue 45 (4) (2014), 331-348. DOI 10.1177/og67010614535833.

Lee, Kelley. The World Health Organization (WHO) (London: Routledge, 2008).

Levine, Ruth. "Open Letter to the Incoming Director-General of the World Health Organization: Time to Refocus." British Medical Journal 333 (7576) (2006), 1015-1017. DOI 10.1136/bmj.39020.383102.68.

Moon, Suerie, Devi Sridhar, Muhammad A. Pate, Ashish K. Jha, Chelsea Clinton, Sophie Delaunay, Valnora Edwin, et al. "Will Ebola Change the Game? Ten Essential Reforms before the Next Pandemic. The Report of the Harvard-LSHTM Independent Panel on the Global Response to Ebola." Health Policy 386 (10009) (2015), 2204-2221. DOI 10.1016/So140-6736(15)oog46-o.

Paun, Christopher. Globalization of Law Enforcement: A Study of Transnational PublicPrivate Partnerships against Intellectual Property Crimes (Doctoral thesis, University of Bremen/Jacobs University, 2012). https://core.ac.uk/reader/46919632.

Phelan, Slexandra L., Mark-Eccleston Turner, Michelle Rourke, Allan Maleche, and Chenguang Wang. "Legal Agreements: Barriers and Enablers to Global Equitable COVID-19 Vaccine Access." The Lancet 396 (10254) (2020), 80o-8o2.

Ravelo, Jenny Lei. “WHO's Budget and the Tasks for the Next Director-General.” Devex, 
3о May 2017. https://www.devex.com/news/who-s-budget-and-the-tasks-for-the-n ext-director-general-90385.

Richter Judith. Public-Private Partnerships and International Health policy-Making: How Can Public Interests Be Safeguarded? (Helsinki: Ministry for Foreign Affairs of Finland, 2004).

Sell, Susan, and Owain David Williams. "Health under Capitalism: A Global Political Economy of Structural Pathogenesis." Review of International Political Economy 27 (1) (2020), 1-25. DOI: 10.108o/og692290.2019.1659842.

Subbaraman, Nidhi. "Who Gets a COVID Vaccine First? Access Plans Are Taking Shape." Nature, 17 September 2020. https://www.nature.com/articles/d41586-020-02 684-9.

WHO (World Health Organization). "Dr Margaret Chan Introduces Proposed Reforms for WHO Priorities." 1 November 2011. https://www.who.int/dg/speeches/2011/refor m_priorities_o1_11/en/.

WHO. Implication of Implementing the Framework of Engagement with Non-State Actors. Non-paper by the WHO Secretariat for Consideration by the Informal Meeting of Member States on 19-23 October. 14 October 2015. https://www.who.int/about/ collaborations/non-state-actors/Implication-implementing-Framework.pdf.

WHO. Evaluation: Update and Proposed Workplan for 2020-2021. Initial Evaluation of the Framework of Engagement with Non-State Actors. Executive Summary. EB146/38 Add.2, 23 December 2019. https://apps.who.int/gb/ebwha/pdf_files/EB146/B146_38 Add2-en.pdf.

WHO. "Endorsements of the Solidarity Call to Action." 2020b. https://www.who.int/ emergencies/diseases/novel-coronavirus-2019/global-research-on-novel-coronavir us-2019-ncov/covid-19-technology-access-pool/endorsements-of-the-solidarity-call -to-action (last accessed 20 October 202O).

WHO. “The Access to COVID-19 Tools (ACT) Accelerator." https://www.who.int/initiati ves/act-accelerator.

Zacher, Mark W., and Tanja J. Keefe. The Politics of Global Health Governance: United by Contagion (New York: Palgrave Macmillan, 2008). 